\title{
Study the accuracy of salivary ferning test as a predictor of ovulation
}

\author{
Dhaval K. Patel*, Darshit G. Prajapati
}

Department of Obstetrics and Gynecology, GMERS Medical College and Hospital, Sola, Ahmedabad, Gujarat, India

Received: 17 April 2018

Accepted: 23 May 2018

\section{*Correspondence:}

Dr. Dhaval K. Patel,

E-mail: drdhaval.7887@gmail.com

Copyright: (c) the author(s), publisher and licensee Medip Academy. This is an open-access article distributed under the terms of the Creative Commons Attribution Non-Commercial License, which permits unrestricted non-commercial use, distribution, and reproduction in any medium, provided the original work is properly cited.

\begin{abstract}
Background: Women probably spent much of their adult life avoiding getting pregnant but when they are actively trying for a baby, it may be taking a little longer time than they hoped. So it is important for the women to know when they are ovulating. Recently, a small hand held microscope (KNOWHEN ovulation microscope) has been developed for the purpose of self-observing ferning patterns in saliva during female fertile period. The purpose of our study is to evaluate the accuracy of salivary ferning test by KNOWHEN ovulation microscope to predict the ovulation and to detect sensitivity and specificity of salivary ferning test and to correlate the salivary ferning with cervical mucus and Trans vaginal sonographic findings (TVS).

Methods: This was a prospective observational type of study conducted on all healthy married women volunteers age between 21-40 years attending gynec OPD in sola civil hospital, Ahmedabad, with regular menstrual cycle From April 2016 to September 2016.

Results: Salivary ferning test by KNOWHEN ovulation microscope is accurate method of detecting ovulation. Its accuracy was $86.5 \%$.

Conclusions: Salivary ferning test is a reliable test to detect fertile period of menstrual cycle. Hence can be use for monitoring ovulation instead of ultrasonography where facility of ultrasonography will not available. Detection of salivary ferning by KNOWHEN microscope has same accuracy as laboratory microscope. KNOWHEN microscope can be use by patient herself to detect fertile period.
\end{abstract}

Keywords: KNOWHEN ovulation microscope, Salivary ferning, TVS

\section{INTRODUCTION}

Women probably spent much of their adult life avoiding getting pregnant but when they are actively trying for a baby, it may be taking a little longer time than they hoped. So it is important for the women to know when they are ovulating. Being infertile is the biggest social stigma faced by Indian women. Ovulation is the process that results in the release of one or more eggs from ovary usually once a month. There is only a small window each month during which one can conceive, typically no longer than about six days. This time leading up to ovulation is most fertile period of month and predicting ovulation is central to conception. The ability to detect the period of potential monthly fertility is of great importance for women in their reproductive years, both in terms of contraception as well as conception. There is increasing demand of women for cheap self test to predict the fertile period in each menstrual cycle. New developments in the area of natural family planning have emerged in recent years. ${ }^{1}$

There are various fertility markers to monitor ovarian function.

\section{Direct methods}

- Trans vaginal ultrasound - follicle size, endometrium, corpus luteum, fluid in cul de sac 
- Hormonal - urinary LH peak, estrogen, progesterone, estrogen conjugates etc.

- Enzymes - B glucoronidase, alkaline phosphatase etc.

\section{Clinical markers}

- BBT, cervical mucus changes, saliva electrical resistance, saliva ferning/crystallization.

In recent years, a small hand held microscope (KNOWHEN ovulation microscope) has been developed and marketed for the purpose of self observing ferning patterns in saliva during female fertile period. It is not advised for avoiding pregnancy but helpful in planning pregnancy. The saliva test has been used to ascertain a woman's fertile period with a success rate of $>90 \% .^{2}$

The purpose of our study is to evaluate the accuracy of salivary ferning test to predict the ovulation and to detect sensitivity and specificity of salivary ferning test and to correlate the salivary ferning with cervical mucus and Trans vaginal sonographic findings (TVS). Trans vaginal sonography is accurate for predicting ovulation by serial monitoring of endometrial thickness and dominant follicle but it is invasive and expensive. If salivary ferning test has high sensitivity and specificity, then it can be used for infertile women for ovulation monitoring as it reduce cost, reduce hospital visits, users friendly and it is self test, woman do it at home, reusable, Noninvasive, suitable for patients who are not willing to undergo repeated TVS or where USG facility not available.

\section{METHODS}

This was a prospective observational type of study conducted on all healthy married women volunteers age between $21-40$ years attending gynec OPD in sola civil hospital, Ahmedabad, with regular menstrual cycle From April 2016 to September 2016.

\section{Sample size:}

The sensitivity of salivary ferning was $95 \%$ and with $95 \%$ confidential interval and $4 \%$ allowable error, the desired sample size was as follow. ${ }^{3}$

$$
\begin{aligned}
& \mathrm{N}=\mathrm{z}^{2} \mathrm{p}(1-\mathrm{p}) / \mathrm{d}^{2(4)} \\
& \mathrm{N}=\text { Sample Size (menstrual cycles) } \\
& \mathrm{p}=\text { sensitivity }(95 \%) \\
& \mathrm{z}=\text { Confidential limit which is } 95 \%=1.96 \\
& \mathrm{~d}=\text { allowable error }(4 \%) \\
& \begin{aligned}
\text { So, } \mathrm{N} & =(1.96)^{2}(0.95)(0.05) /(0.04)^{2} \\
& =114
\end{aligned}
\end{aligned}
$$

\section{Inclusion criteria}

Healthy married women age between $21-40$ years with regular menstrual cycle (26-34 days).

\section{Exclusion criteria}

Exclusion criteria were pelvic inflammatory disease (PID); patient taking ovulation induction drugs, supplemental estrogen, hormonal contraceptives; refuse to give consent.

\section{Methodology}

107 healthy married women volunteers with 114 menstrual cycles were included in our study as per inclusion criteria. All the eligible patients were given patient information sheet and were included in study after obtaining written informed consent.

Patient will be asked to come on day $6,8,10,12,14,16$, 18 of menstrual cycle and post ovulation day 7 to see progestogenic effect on endometrium.

During each visit, following will be examined.

\section{Salivary ferning}

- Test saliva in morning after $2-3$ hours of fasting.

- Saliva should be collected from under the tongue as salivary glands located below the tongue. Collect dab of saliva and place it on the surface of lens and on slide.

- Try to avoid air bubbles and allow the sample to dry for at least five minutes and viewing the presence or absence of salivary ferning and degree of ferning by KNOWHEN ovulation microscope and laboratory microscope and compare with concomitant sonographic findings and cervical mucus.

- Ferning pattern is describe as negative "0" (Non Fertile period), Positive " +1 " (Slight ferning indicate beginning or ending of fertile period), Positive " +2 " (good ferning indicate fertile period). ${ }^{5}$

\section{Cervical mucus}

- Cervical mucus should be collected by syringe and viewing for its stretchability ("spinnbarkeit") and its ability to fern.

- Ferning pattern will be seen by laboratory microscope.

\section{Transvaginal sonography (TVS)}

During each visit, following parameters will be reviewed.

- Follicular growth

- Endometrial thickness

- Changes in the pattern of endometrium

- Signs of ovulation

- Presence or Absence of Ecogenic endometrium on day 7 post ovulation.

TVS will be done by Mindray Model; DP-50 
TVS examination are considered as a gold standard for detection of ovulation, by demonstrating the presence of dominant follicle (minimum $18 \mathrm{~mm}$ diameter) or a corpus luteum at the site of follicular rupture or fluid in pouch of duglas. If none are observed, the cycle determines to be anovulatory. ${ }^{6}$

Following parameters will be measured.

- Sensitivity, Specificity, Positive Predictive Value, Negative Predictive Value of Salivary Ferning.

- Degree of agreement will be done by using kappa statistics

A P value $<0.05$ was considered statistically significant. . Yates ${ }^{\text {ee }}$ correction was applied when expected frequency was less than 5 in more than $20 \%$ of cells. Statistical analysis will be done using Microsoft excel and Epi Info software.

\section{RESULTS}

A total of 107 healthy married women volunteers were recruited in our study as per inclusion criteria and data were obtained from observation of 114 menstrual cycles. Out of 114 menstrual cycles studied, 79 (69\%) cycles were documented as being ovulatory cycle by ultrasonographic evaluation and $25(22 \%)$ cycles were documented as being anovulatory cycle because of absence of sonographic criteria of ovulation while 10 (9\%) women (1 cycle / woman) lost follow up during their study period and not completed the study. So total 104 menstrual cycles completed the study for salivary ferning, cervical ferning and transvaginal sonography examination.

Table 1: Demographic characteristics (age distributions) of study population.

\begin{tabular}{|lll|}
\hline Age groups (yrs) & No. of cases & Percentage \\
\hline $21-25$ & 42 & 39.25 \\
\hline $26-30$ & 49 & 45.79 \\
\hline $31-35$ & 14 & 13.09 \\
\hline $36-40$ & 2 & 1.87 \\
\hline Mean \pm SD & $27.11 \pm 3.43$ & \\
\hline Median & 26 & \\
\hline Range & $22-36$ & \\
\hline
\end{tabular}

Table 2: Relationship between salivary ferning by KNOWHEN microscope and ovulation.

\begin{tabular}{|llll|}
\hline $\begin{array}{l}\text { Salivary ferning by } \\
\text { KNOWHIEN } \\
\text { microscope }\end{array}$ & \multicolumn{2}{c}{ Ovulation } & Total \\
\hline Present & 70 & 5 & 75 \\
\hline Absent & 9 & 20 & 29 \\
\hline Total & 79 & 25 & 104 \\
\hline
\end{tabular}

Table 2 shows relationship between salivary ferning by KNOWHEN microscope and ovulation. Ferning was detected by KNOWHEN microscope in 70 out of 79 cases around the time of ovulation while it was detected in 5 cases where ovulation was absent as per the ultrasonographic evaluation. Hence Detection of salivary ferning by KNOWHEN microscope had a sensitivity of $88.6 \%$ and a specificity of $80 \%$, a positive predictive value of $93.3 \%$ and a negative predictive value of $69 \%$. Accuracy of KNOWHEN microscope was $86.54 \%$.

Table 3: Comparison of validity parameters for detecting salivary ferning between KNOWHEN microscope and laboratory microscope.

\begin{tabular}{|llll|}
\hline Parameters & $\begin{array}{l}\text { KNOWHIEN } \\
\text { microscope }\end{array}$ & $\begin{array}{l}\text { Laboratory } \\
\text { microscope }\end{array}$ & $\begin{array}{l}\text { P } \\
\text { value }\end{array}$ \\
\hline Sensitivity (\%) & 88.6 & 94.9 & 0.74 \\
\hline Specificity (\%) & 80 & 80 & 1 \\
\hline $\begin{array}{l}\text { Positive } \\
\text { predictive } \\
\text { value (\%) }\end{array}$ & 93.3 & 93.8 & 0.97 \\
\hline $\begin{array}{l}\text { Negative } \\
\text { predictive } \\
\text { value (\%) }\end{array}$ & 69 & 83.3 & 0.38 \\
\hline Accuracy & 86.54 & 91.35 & 0.79 \\
\hline
\end{tabular}

Table 3 shows Comparison of various Validity parameters for detecting Salivary Ferning between KNOWHEN Microscope and Laboratory Microscope around the time of Ovulation. Sensitivity of detecting salivary ferning around the time of ovulation by KNOWHEN microscope and laboratory microscope were $88.6 \%$ and $94.9 \%$ respectively and $p$ value was 0.74 which was not statistically significant. Similarly, the specificity of both KNOWHEN microscope and laboratory microscope for salivary ferning was $80 \%$ and $\mathrm{p}$ value was 1 which was not statistically significant. Positive predictive value of detecting salivary ferning around the time of ovulation by KNOWHEN microscope and laboratory microscope were $93.3 \%$ and $93.8 \%$ respectively and $\mathrm{p}$ value was 0.97 which was not statistically significant. Similarly, the Negative predictive value of KNOWHEN microscope and laboratory microscope for salivary ferning were $69 \%$ and $83.3 \%$ respectively and $\mathrm{p}$ value was 0.38 which was not statistically significant. Accuracy of detecting salivary ferning by KNOWHEN microscope was $86.54 \%$ as compared to $91.35 \%$ in laboratory microscope and $\mathrm{p}$ value was 0.79 which was not statistically significant.

Table 4 shows Comparison of various Validity parameters between Salivary Ferning by KNOWHEN Microscope and Cervical Ferning by Laboratory Microscope. Sensitivity of detecting salivary ferning by KNOWHEN microscope and detecting cervical ferning by laboratory microscope around the time of ovulation were $88.6 \%$ and $92.41 \%$ respectively and $\mathrm{p}$ value was 0.84 which was not statistically significant. Similarly, the 
Specificity of KNOWHEN microscope for salivary ferning and laboratory microscope for cervical ferning were same $(80 \%)$ and $p$ value was 1 which was not statistically significant. Positive predictive value of detecting salivary ferning by KNOWHEN microscope and detecting cervical ferning by laboratory microscope around the time of ovulation were $93.3 \%$ and $93.59 \%$ respectively and $\mathrm{p}$ value was 1 which was not statistically significant. Similarly, the Negative predictive value of KNOWHEN microscope for salivary ferning and laboratory microscope for cervical ferning were $69 \%$ and $76.92 \%$ respectively and $\mathrm{p}$ value was 0.62 which was not statistically significant. Accuracy of detecting salivary ferning by KNOWHEN microscope and detecting cervical ferning by laboratory microscope around the time of ovulation were $86.54 \%$ and $89.42 \%$ respectively and $\mathrm{p}$ value was 0.87 which was not statistically significant.

Table 4: Comparison of Validity parameters between Salivary Ferning by KNOWHEN Microscope and Cervical Ferning by Laboratory Microscope.

\begin{tabular}{|c|c|c|c|}
\hline $\begin{array}{l}\text { Validity } \\
\text { parameters }\end{array}$ & $\begin{array}{l}\text { Salivary } \\
\text { ferning by } \\
\text { KNOWHEN } \\
\text { microscope }\end{array}$ & $\begin{array}{l}\text { Cervical } \\
\text { ferning }\end{array}$ & $\begin{array}{l}\mathrm{P} \\
\text { value }\end{array}$ \\
\hline Sensitivity (\%) & 88.6 & 92.41 & 0.84 \\
\hline Specificity (\%) & 80 & 80 & 1 \\
\hline $\begin{array}{l}\text { Positive } \\
\text { Predictive } \\
\text { Value }(\%)\end{array}$ & 93.3 & 93.59 & 1 \\
\hline $\begin{array}{l}\text { Negative } \\
\text { Predictive } \\
\text { Value }(\%)\end{array}$ & 69 & 76.92 & 0.62 \\
\hline Accuracy (\%) & 86.54 & 89.42 & 0.87 \\
\hline
\end{tabular}

Table 5: Grade of salivary ferning by KNOWHEN microscope in relation with ovulation.

\begin{tabular}{|c|c|c|c|}
\hline \multirow{2}{*}{$\begin{array}{l}\text { Day relative } \\
\text { to ovulation }\end{array}$} & \multicolumn{3}{|c|}{$\begin{array}{l}\text { Grade of salivary ferning by } \\
\text { KNOWHEN microscope }\end{array}$} \\
\hline & $\begin{array}{l}\text { o ferning } \\
(\%)\end{array}$ & $\begin{array}{l}\text { +1 ferning } \\
(\%)\end{array}$ & $\begin{array}{l}\text { +2 ferning } \\
(\%)\end{array}$ \\
\hline-6 & $44(55.7)$ & $35(44.3)$ & $0(0)$ \\
\hline-4 & $13(16.5)$ & $64(81)$ & $2(2.5)$ \\
\hline-2 & $9(11.4)$ & $34(43)$ & $36(45.6)$ \\
\hline 0 & $9(11.4)$ & $44(55.7)$ & $26(32.9)$ \\
\hline
\end{tabular}

Table 5 shows Relationship of Grade of Salivary Ferning by KNOWHEN Microscope with Ovulation. On the day of ovulation, +1 salivary ferning and +2 salivary ferning by KNOWHEN microscope was present in $55.7 \%$ and $32.9 \%$ cases respectively while ferning was absent in $11.4 \%$ cases on the day of ovulation. Two day prior to ovulation, +1 salivary ferning and +2 salivary ferning was present in $43 \%$ and $45.6 \%$ cases respectively while ferning was absent in $11.4 \%$ cases. Similarly, four day prior to ovulation, +1 salivary ferning and +2 salivary ferning was present in $81 \%$ and $2.5 \%$ cases respectively while ferning was absent in $16.5 \%$ cases. Similarly, six day prior to ovulation, ferning was absent in $55.7 \%$ cases and +1 ferning was present in $44.3 \%$ cases.

Table 6: Relationship of Grade of Salivary Ferning by KNOWHEN Microscope with Follicle size.

\begin{tabular}{|c|c|c|c|}
\hline \multirow{2}{*}{$\begin{array}{l}\text { Follicle size } \\
(\mathrm{mm})\end{array}$} & \multicolumn{3}{|c|}{$\begin{array}{l}\text { Salivary ferning by KNOWHEN } \\
\text { microscope }\end{array}$} \\
\hline & $\begin{array}{l}0 \text { ferning } \\
(\%)\end{array}$ & $\begin{array}{l}\text { +1 ferning } \\
(\%)\end{array}$ & $\begin{array}{l}+2 \text { ferning } \\
(\%)\end{array}$ \\
\hline 16 & $16(38.1)$ & $25(59.5)$ & $1(2.4)$ \\
\hline 18 & $1(2.3)$ & $39(90.7)$ & $3(7)$ \\
\hline 20 & $0(0)$ & $21(60)$ & $14(40)$ \\
\hline 22 & $0(0)$ & $18(56.2)$ & $14(43.8)$ \\
\hline$\geq 24$ & $0(0)$ & $4(33.3)$ & $8(66.7)$ \\
\hline
\end{tabular}

The table included only cases where ovulation and ferning were detected.

Table 6 shows Relationship of Grade of Salivary Ferning by KNOWHEN Microscope with follicle size. At $16 \mathrm{~mm}$ follicular size by TVS, +1 salivary ferning and +2 salivary ferning were detected in $59.5 \%$ and $2.4 \%$ cases respectively. At $18 \mathrm{~mm}$ follicular size, +1 salivary ferning and +2 salivary ferning were detected in $90.7 \%$ and $7 \%$ cases respectively. At $20 \mathrm{~mm}$ follicular size, +1 salivary ferning and +2 salivary ferning were detected in $60 \%$ and $40 \%$ cases respectively. . At $22 \mathrm{~mm}$ follicular size, +1 salivary ferning and +2 salivary ferning were detected in $56.2 \%$ and $43.8 \%$ cases respectively while follicle size of $24 \mathrm{~mm}$ or more, +1 salivary ferning and +2 salivary ferning were detected in $33.3 \%$ and $66.7 \%$ cases respectively.

Table 7: Relationship between salivary ferning by KNOWHEN microscope and endometrial thickness.

\begin{tabular}{|lll|}
\hline $\begin{array}{l}\text { Endometrial } \\
\text { thickness }(\mathbf{m m})\end{array}$ & \multicolumn{2}{l|}{ Salivary ferning (\%) } \\
\hline $5.1-6.0$ & Present $(\%)$ & Absent $(\%)$ \\
\hline $6.1-7.0$ & $37(4.1)$ & $75(94.9)$ \\
\hline $7.1-8.0$ & $58(80.6)$ & $42(53.2)$ \\
\hline $8.1-9.0$ & $63(94)$ & $4(6)$ \\
\hline
\end{tabular}

The table included only cases where ovulation was detected.

Table 8: Incidence of different signs of ovulation at the time of ovulation.

\begin{tabular}{|lll|}
\hline Sign of ovulation & No. of cases & Percentage \\
\hline Dominant Follicle & 79 & 100 \\
\hline Fluid in POD & 61 & 77.22 \\
\hline Corpus Luteum & 52 & 65.82 \\
\hline
\end{tabular}

Table 7 shows relationship between salivary ferning by KNOWHEN microscope and endometrial thickness. 
Salivary ferning was absent in $95 \%$ cases when endometrial thickness was 5.1-6.0 mm while at 6.1-7.0 $\mathrm{mm}$ endometrial thickness, salivary ferning was present in $47 \%$ cases and absent in $53 \%$ cases. Similarly, salivary ferning was present in $81 \%$ cases and $94 \%$ cases when endometrial thickness was 7.1-8.0 $\mathrm{mm}$ and $8.1-9.0 \mathrm{~mm}$ respectively.
Table 8 shows incidence of different signs of ovulation at the time of ovulation. Dominant follicle (minimum $18 \mathrm{~mm}$ diameter) was seen in $100 \%$ of cases while fluid in POD was seen in $77.22 \%$ of cases and corpus luteum at the site of follicular rupture was seen in $65.82 \%$ of cases.

Table 9: Relationship between Appearance of good (+2) Salivary Ferning to Ovulation time interval.

\begin{tabular}{|llll|}
\hline $\begin{array}{l}\text { Interval (day relative to } \\
\text { ovulation) }\end{array}$ & +2 Salivary Ferning & & P value \\
\hline-4 & KNOWHEN microscope (\%) & Laboratory microscope (\%) & 0.75 \\
\hline-2 & $2(3.17)$ & $2(2.94)$ & 0.92 \\
\hline 0 & $39(61.90)$ & $43(63.24)$ & 0.91 \\
\hline
\end{tabular}

The table included only cases where ovulation and +2 ferning were detected.

Table 10: Comparison of assessment of salivary ferning between KNOWHEN microscope and laboratory microscope.

\begin{tabular}{|c|c|c|c|c|c|c|c|}
\hline \multirow{2}{*}{$\begin{array}{l}\text { Observations with } \\
\text { KNOWHEN } \\
\text { Microscope }\end{array}$} & \multicolumn{3}{|c|}{$\begin{array}{l}\text { Observations with Laboratory } \\
\text { Microscope }\end{array}$} & \multirow{2}{*}{ Total } & \multirow{2}{*}{$\begin{array}{l}\text { Observed } \\
\text { agreements }\end{array}$} & \multirow{2}{*}{$\begin{array}{l}\text { Kappa } \\
\text { agreement }\end{array}$} & \multirow{2}{*}{$\begin{array}{l}95 \% \\
\mathrm{CI}\end{array}$} \\
\hline & 0 ferning & $\begin{array}{l}+1 \\
\text { ferning }\end{array}$ & +2 ferning & & & & \\
\hline 0 ferning & 4 & 4 & 1 & 9 & \multirow{4}{*}{$\begin{array}{l}88.61 \% \text { of } \\
\text { observations }\end{array}$} & \multirow{4}{*}{0.62} & \multirow{4}{*}{$\begin{array}{l}0.428- \\
0.813\end{array}$} \\
\hline+1 ferning & 0 & 3 & 4 & 7 & & & \\
\hline+2 ferning & 0 & 0 & 63 & 63 & & & \\
\hline Total & 4 & 7 & 68 & 79 & & & \\
\hline
\end{tabular}

Table 9 shows relationship between appearance of +2 salivary ferning to ovulation time interval. On the day of ovulation, good (+2) salivary ferning was detected in $34.92 \%$ cases and $33.82 \%$ cases by KNOWHEN microscope and laboratory microscope respectively and $\mathrm{p}$ value was 0.91 which was not statistically significant while in $61.90 \%$ cases and $63.24 \%$ cases, good $(+2)$ salivary ferning was detected by KNOWHEN microscope and laboratory microscope respectively, 48 hours prior to ovulation and $\mathrm{p}$ value was 0.92 which was not statistically significant. Hence, in majority (96-97\%) of cases, good (+2) salivary ferning occurs within 24-48 hours prior to ovulation.

Table 10 shows comparison of assessment of salivary ferning between KNOWHEN microscope and laboratory microscope. Study shows that the number of observed agreements were 70 (88.61\% of the observations) and the number of agreements expected by chance were 55.3 (70\% of the observations). The kappa agreement was 0.62 which indicates a substantial agreement (95\% CI $0.428-0.813)$. Strength of agreement was considered to be good.

\section{DISCUSSION}

In the study conducted by Melnick $\mathrm{H}$ et al, they found that the KNOWHEN microscope had $96.5 \%$ sensitivity,
83.3\% specificity, $93.3 \%$ positive predictive value and $90.9 \%$ negative predictive value. ${ }^{7}$ In their study, the Accuracy of KNOWHEN microscope was $92.7 \%$. While in present study, the KNOWHEN ovulation microscope had $88.6 \%$ sensitivity, $80 \%$ specificity, $93.3 \%$ positive predictive value and $69 \%$ negative predictive value. In present study, the Accuracy of KNOWHEN ovulation microscope was $86.5 \%$ and $p$ value was 0.74 which was not statistically significant.

Rotta L et al conducted study on total 120 menstrual cycles, used mini-microscope for detecting salivary ferning had found the sensitivity $78.5 \%$ and specificity $84 \% .^{8}$ Braat DD et al had conducted study on 30 women found the sensitivity and specificity of the test were $53 \%$ and $72 \%$ respectively. ${ }^{9}$ Another study, Guida $\mathrm{M}$ et al conducted prospective study on 40 women and data were obtained from observation of 148 cycles, used minimicroscope for detecting salivary ferning had found the sensitivity $36.8 \%$ and $58.7 \%$ cases were uninterpretable in their study. ${ }^{10}$ Salmassi A et al conducted study on 47 infertile women taking part in artificial reproductive technology program. ${ }^{11}$ In their study salivary ferning was evaluated by geratherm ovu control microscope showed a sensitivity of $80 \%$ and specificity of $78 \%$. In the study conducted by Melnick $\mathrm{H}$ et al, used KNOWHEN microscope had sensitivity $96.5 \%$ and specificity $83.3 \% .^{7}$ In Present study, KNOWHEN microscope showed a 
sensitivity of $88.6 \%$ and specificity of $80 \%$ while laboratory microscope had a sensitivity of $94.9 \%$ and a specificity of $80 \%$.

Rollason $\mathbf{J}$ et al, conducted pilot, prospective, observational study on total 8 infertile patients with 18 menstrual cycles for comparing Duofertility monitor with ultrasound in infertile women, they found that the collapse of previously seen follicle were seen in $100 \%$ of cases and fluid in POD were seen in $50 \%$ of cases as a signs of ovulation. ${ }^{6}$ In present study, the commonest sign of ovulation detected was dominant follicle which was detected in $100 \%$ of cases followed by fluid in POD, detected in $77.22 \%$ of cases followed by corpus luteum, detected in $65.82 \%$ of cases.

In the study conducted by Barbato $\mathrm{M}$ et al, the duration of fertile period (duration of ferning) was 6.2 days. $^{12}$ Similarly, in the study of Fehring RJ et al, the duration of fertile period (duration of ferning) was also 6.2 days. ${ }^{13-15}$ In the study conducted by Pardo Carmona B et al, the duration of fertile period (duration of ferning) was 6.6 days. While in Present study, the duration of fertile period was 6.8 days. $^{5}$

Study conducted by Pattanasuttinont $\mathrm{S}$ et al showed that in $36.7 \%$ cases, peak salivary ferning occurred within \pm 3 days of ovulation in clomiphene citrate stimulated cycles. ${ }^{4}$ There were two peaks of median salivary ferning, one was two days prior to ovulation and other was five days post ovulation. There was no correlation between the peak salivary ferning day and day of ovulation detected by TVS. In another Study conducted by Fehring RJ et al showed that in $76.2 \%$ cases, peak salivary ferning occurred within \pm 3 days of LH surge. ${ }^{13}$ While in present study, the peak salivary ferning occurred in $96.8 \%$ cases within 2 days prior to ovulation. Hence, according to this study, ovulation is most likely to occur within 24-48 hours of peak salivary ferning..

\section{CONCLUSION}

Salivary ferning test by KNOWHEN ovulation microscope is accurate method of detecting ovulation. Accuracy of KNOWHEN ovulation microscope was $86.5 \%$. There was strong correlation between salivary ferning and cervical ferning. The commonest sign of ovulation detected by TVS was dominant follicle $(>=18 \mathrm{~mm}$ ) followed by fluid in POD and corpus luteum at the site of follicular rupture. Ovulation is most likely to occur within 24-48 hours of good (+2) salivary ferning. The Sensitivity of detecting salivary ferning by KNOWHEN microscope and laboratory microscope were $88.6 \%$ and $94.9 \%$ respectively and specificity of both microscopes were $80 \%$ which was not statistically significant. So it can be use as a substitute of each other. Average duration of salivary ferning (duration of fertile period) was 6.8 days.
So, Salivary ferning test is a reliable test to detect fertile period of menstrual cycle. Hence can be use for monitoring ovulation instead of ultrasonography where facility of ultrasonography is not available. Detection of salivary ferning by KNOWHEN microscope has same accuracy as laboratory microscope. KNOWHEN microscope can be use by woman herself to detect fertile period and it is user's friendly. Salivary ferning for monitoring of ovulation in infertile women with timed ultrasonography visits based on salivary ferning finding will reduce the number of hospital visits and reduce economical burden on women.

\section{ACKNOWLEDGMENTS}

We thank our colleagues and seniors from GMERS medical college, sola, Ahmedabad who provided insight and expertise that greatly assisted the research.

\section{Funding: No funding sources Conflict of interest: None declared \\ Ethical approval: The study was approved by the Institutional Ethics Committee of GMERS medical college sola, Ahmedabad}

\section{REFERENCES}

1. Guida M, Tommaselli GA, Pellicano M, Palomba S, Nappi C. An overview of the effectiveness of natural family planning. Gynecol endocrinol. 1997;11:20319.

2. Galati G, Trapani E, Yacoub M, Toccaceli MR, Galat GM, Firell F, et al. A new test for human female ovulation diagnosis. Int Rev Med Sci. 1994;6(1).

3. Hajian-Tilaki K. Sample size estimation in diagnostics test studies of biomedical informatics. J Biomed Informatics. 2014;48:193-204.

4. Pattanasuttinont S, Sereepapong W, Suwajanakorn S. The salivary ferning test and ovulation in clomiphene citrate-stimulated cycles. J Med Assoc Thai. 2007;90(5):876-83.

5. Pardo-Carmona B, Moyano M, Fernandez R, PerezMarin C. Saliva crystallization as a means of determining optimal mating time in bitches. J Small Animal Prac. 2010;51:437-42.

6. Rollason J, Outtrim J, Mathur R. A pilot study comparing the DuoFertility monitor with ultrasound in infertile women. Int $\mathbf{J}$ Womens Health. 2014;6:657-62.

7. Melnick H, Goudas VT. The detection of a salivary ferning pattern using the knowhen ovulation monitoring system as an indication of ovulation. J Women's health Care. 2015;4:235.

8. Rotta L, Matechova E, Cerny M, Pelak Z. Determination of the fertile period during the menstrual cycle in women by monitoring changes in crystallization of saliva with the PC 2000 IMPCON mini microscope. Ceska gynecol. 1992;57:340-52. 
9. Braat DD, Smeenk JM, Manger AP, Thomas CM, Veersema S. Saliva test as ovulation predictor. Lancet. 1998;352:1283-4.

10. Guida M, Tommaselli GA, Palomba S, Pellicano M, Moccia G. Efficacy of methods for determining ovulation in a natural family planning program. Fertil Steril. 1999;72:900-4.

11. Salmassi A, Schmutzler AG, Püngel F, Schubert M, Alkatout I. Ovulation detection in saliva, is it possible. Gynecol Obstet Invest. 2013;76:171-6.

12. Barbato M, Pandolfi A, Guida M. A new diagnostic aid for natural family planning. Adv Contracept. 1993;9:335-40.

13. Fehring RJ, Gaska N. Evaluation of the lady free biotester in determining the fertile period. Contraception. 1998;57(5):325-8.
14. Fehring R, Schlaff W. Accuracy of the Ovulon fertility monitor to predict and detect ovulation. J Nurse Midwif. 1998;43:117-20.

15. Fehring R. Methods used to predict ovulation, a comparative study. J Obstet Gynecol Neonatal Nurs. 1990;19:233-7.

Cite this article as: Patel DK, Prajapati DG. Study the accuracy of salivary ferning test as a predictor of ovulation. Int J Reprod Contracept Obstet Gynecol 2018;7:2699-705. 